\title{
COOLING OF HIGH HEAT FLUX FLAT SURFACE WITH NANOFLUID ASSISTED CONVECTIVE LOOP: EXPERIMENTAL ASSESSMENT
}

\begin{abstract}
Experimental investigation was conducted on the thermal performance and pressure drop of a convective cooling loop working with $\mathrm{ZnO}$ aqueous nanofluids. The loop was used to cool a flat heater connected to an AC autotransformer. Influence of different operating parameters, such as fluid flow rate and mass concentration of nanofluid on surface temperature of heater, pressure drop, friction factor and overall heat transfer coefficient was investigated and briefly discussed. Results of this study showed that, despite a penalty for pressure drop, $\mathrm{ZnO} /$ water nanofluid was a promising coolant for cooling the micro-electronic devices and chipsets. It was also found that there is an optimum for concentration of nanofluid so that the heat transfer coefficient is maximum, which was wt. $\%=0.3$ for $\mathrm{ZnO} /$ water used in this research. In addition, presence of nanoparticles enhanced the friction factor and pressure drop as well; however, it is not very significant in comparison with those of registered for the base fluid.
\end{abstract}

\section{Introduction}

Continuous progress in designing the microprocessors and micro-electronic chipsets has led to an increase in demands for some specific types of cooling systems with the capability of high heat flux removal. It is predicted that soon enough, the heat produced by the micro-electronic circuits reaches to $100 \mathrm{~W} / \mathrm{cm}^{2}$, which implies that conventional cooling systems cannot provide sufficient cooling capacity to cool down the future processors. This is because thermal conductivity of conventional

\footnotetext{
${ }^{1}$ School of Engineering and Technology, Purdue University, IUPUI, Indianapolis, USA. Email: amir.arya87@gmail.com

${ }^{2}$ Lamar University, Department of Mechanical Engineering, Beaumont, TX 77710, USA. Email: saeed.shahmiri@gmail.com

${ }^{3}$ Faculty of Chemical, Petroleum and Gas Engineering, Semnan University, Semnan, Iran. Emails: vahid.nikkhah7@gmail.com,mohamadmohsensarafraz@gmail.com
} 
coolants such as air or water is limited; therefore, there is a need to investigate new-engineered coolants for advanced thermal engineering systems. Nanofluids are a new generation of coolants comprising solid particles with average size of 0-100 nm dispersed within the conventional coolants such as water or oil. Normally, solid particles are metallic solids, which have higher thermal conductivity than liquids and other solid materials. It has been shown that nanofluids represent better thermo-physical properties such as thermal conductivity, density and viscosity. In addition, they represent lower pressure drop in comparison with micro-fluids.

Much effort has been made to investigate the potential application of nanofluids in cooling of microelectronic devices. For example, Ghasemi et al. [1] investigated the influence of nanofluid on the convective heat transfer and thermal performance of a heat sink. $\mathrm{TiO}_{2}$ aqueous nanofluid was used and it was found that thermal resistance of the system decreased, while the heat transfer coefficient of the system was higher than that of reported for the base fluid (water). Sarafraz et al. [2] performed some experiments on the thermal performance of a cooling loop working with liquid gallium and $\mathrm{CuO}$ /water nanofluid. They showed that despite the promising performance of liquid gallium, $\mathrm{CuO} /$ water nanofluid represents lower pressure drop and pumping power and can be a better alternative for cooling systems. Nazari et al. [3] compared the thermal performance of a central processor unit (CPU) cooler for different nanofluids including alumina and Carbon Nano Tube (CNT) nanofluids and different base fluids. Their results showed a 4\% increase in the heat transfer coefficient in the case of ethylene glycol (30\%). An increase of $6 \%$ was also reported by using $0.5 \%$ volume fraction of alumina nanofluid. The best heat transfer enhancement (about 13\%) was related to CNT nanofluids with the volume fraction of $0.25 \%$ for the flow rate of $21 \mathrm{ml} / \mathrm{s}$.

Ghasemi et al. [4] investigated the influence of geometry of channel on the thermal performance of a mini-channel CPU cooler and showed that, with an increase in diameter of channel, pressure drop in the heat sink reduces. They optimized the performance of the CPU cooler based on the diameter of the channels. $\mathrm{Hu}$ et al. [5] designed a water-cooled thermo-electric system for CPU cooling with the capacity to save energy and to prevent from condensation on CPU. The system worked with air and water and showed a reasonable thermal performance at sever operating conditions.

The utilization of nanofluids for cooling the computer chips was investigated by Rafati et al. [6]. For this study, different base fluids were used including the water and ethylene glycol. In addition, three different nanofluids were used as the coolant. Results demonstrated that heat transfer rate was enhanced when nanofluid was used. Sarafraz et al. in a series of experiments on different nanoparticles dispersed in conventional based fluids such as alumina[7, 8], copper oxide [9-11], silver [12, 13], zirconia [14] and carbon nanotube [15-18] and found out that fouling is the major disadvantage of the nanofluids and depending on the type of the heat exchanger, different rate of fouling can be seen within the system. In another study on the thermal performance of a thermosyphon, Sarafraz et al. [19] showed 
that, although nanofluids offer the better thermal performance in comparison with traditional coolants, there are challenges, which limit the application of the nanofluids in different heat exchanging systems. Boiling heat transfer limitation $[20,21]$, formation of bubble blanket [22-24] and poor thermal conductivity and its low contribution in boiling heat transfer of base fluid [25, 26] are examples of these challenges. These challenges not only hinder the commercialization of the nanofluids in cooling systems but also motivate the experts for doing further research on other nanofluids to select the best potential coolant for the convective/boiling cooling cycles [27].

In the present work, thermal performance of a convective cooling loop is experimentally investigated for $\mathrm{ZnO}$ aqueous nanofluids at mass concentrations of $0.1 \%$ to $0.4 \%$. Nanofluids are prepared using two-step method and are stabilized using ultrasonic and Nonyl Phenol Ethoxilate (NPE) surfactant. The heat transfer characteristics of $\mathrm{ZnO}$ /water nanofluid including temperature, overall heat transfer coefficient, pressure drop and friction factor is experimentally assessed and discussed, when the cooling loop is used to cool a flat heater. The heater is geometrically similar to the processor units and results can be used for further research on CPU and microelectronics.

\section{Experimental}

\subsection{Test rig}

Fig. 1 represents the schematic diagram of the test rig used in this research. Nanofluids are stored in the tank and are pumped using a pump into (manufactured by DAB Co) the loop. The flow rate of the pump is controlled with a bypass cycle and flow rate is measured using ultrasonic flow meter (manufactured by Flownetix Co). Temperature and pressure of the fluid before and after the test section is constantly measured using two RTDs and two pressure transmitters. A coppermade liquid block is used for cooling the flat heater installed on the top of the flat

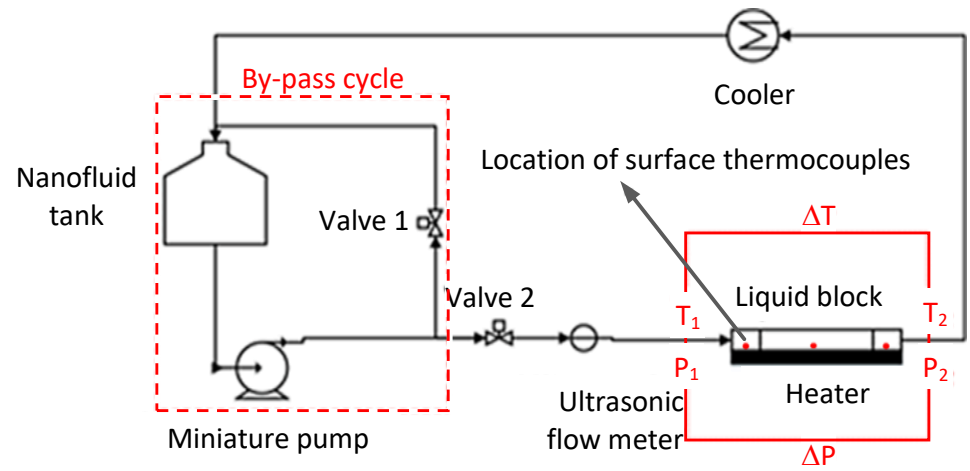

Fig. 1. Schematic diagram of the experimental setup used in this research 
heater. Silicone paste was used between liquid block and the flat heater to reduce the thermal resistance between thermocouple and its thermo-well. The geometrical properties of the flat heater are similar to conventional processor units (CPU), so this convective loop can be used for cooling any processors.

Three different k-type thermocouples were installed on the surface of the heater to monitor the surface temperature and prevent from overheating the heater. The arithmetic average of the temperature readings from the thermocouples are considered as the surface temperature of the heater $\left(T_{w}\right)$. Thermocouples were connected to a Proportional-Integral-Differential (PID) controller to control the threshold of the temperature. Heater was connected to a regulator $\mathrm{AC}$ transformer (manufactured by Emersun Co). By applying different voltages to the heater, different heat fluxes are applied into the liquid block. Then, the temperature of the coolant is reduced to tank temperature using an airside cooler. Noticeably, for better comparison, the temperature of tank is constant at any given heat fluxes.

To measure the overall heat transfer coefficient $(U)$, equation 1 was used, which has been obtained by an energy balance between heater and liquid block:

$$
U=\frac{\rho v C p\left(T_{\text {out }}-T_{\text {in }}\right)}{A \Delta T_{L M T D}}
$$

and,

$$
\Delta T_{L M T D}=\frac{\left(T_{w}-T_{\text {out }}\right)-\left(T_{w}-T_{\text {in }}\right)}{\ln \left(\frac{\left(T_{w}-T_{\text {out }}\right)}{\left(T_{w}-T_{\text {in }}\right)}\right)}
$$

where, $\rho$ is density $\left(\mathrm{kg} / \mathrm{m}^{3}\right), v$ is the flow rate of fluid $\left(\mathrm{m}^{3} / \mathrm{s}\right), C p$ is the specific heat, $T_{\text {in }}$ and $T_{\text {out }}$ are temperature of outlet and inlet sections, respectively. $T_{w}$ is the arithmetic average of the three $\mathrm{k}$ type thermocouple readings and $A$ is the heat transfer area of the heater. The Darcy-Weisbach friction factor was estimated with the following equation:

$$
f=\frac{\Delta P_{n f}}{\frac{L}{D_{\text {hyd. }}} \frac{2 G^{2}}{\rho_{n f}}}
$$

For this equation, $L$ is the exact vertical distance between two ports of heat exchanger, $G$ is the mass velocity, which is the product of the density, $\rho$ and volumetric fluid flow rate and $\Delta P$ is the pressure drop obtained during the experiments.

Reynolds number is also calculated with the following equation:

$$
\operatorname{Re}=\frac{\rho_{n f} v D}{\mu_{n f}}
$$

$\rho$ is density $\left(\mathrm{kg} / \mathrm{m}^{3}\right)$ and $n f$ stands for nanofluid, $v$ is the velocity of fluid, $D$ is the hydraulic diameter of the liquid block (m) and $\mu$ is the viscosity of fluid $\left(\mathrm{kg} \mathrm{m} / \mathrm{s}^{2}\right)$.

The uncertainty of experiments was analyzed with Kline-McClintock equation [28] and the overall uncertainty was found to be $9.8 \%$. 


\subsection{Nanofluid preparation}

Nanoparticles were purchased from US nano and used as purchased (no mechanical treatments were applied). A two-step method was used for preparing the nanofluids. In order to check the quality of the nanoparticles and also the prepared nanofluids, the morphology, size and purity of particles were analyzed using scanning electron microscopic image (SEM), Transmission Electron Microscopic image (TEM), and x-ray diffraction test (XRD). To prepare the nanofluids, $\mathrm{ZnO}$ nanoparticles of required weight were uniformly dispersed in water at with mass fractions of $0.1 \%-0.4 \%$. Nonyl-Phenol Ethoxylate was added to the nanofluids at $0.1 \%$ of general volume of base fluid to prevent it from any changes in thermo-physical properties. The Ultrasonic at power of $400 \mathrm{~W}$ and at frequency of $40 \mathrm{kHz}$ was applied to the nano-fluids to crack any agglomeration or clusters of nanoparticles dispersed within the base fluid.

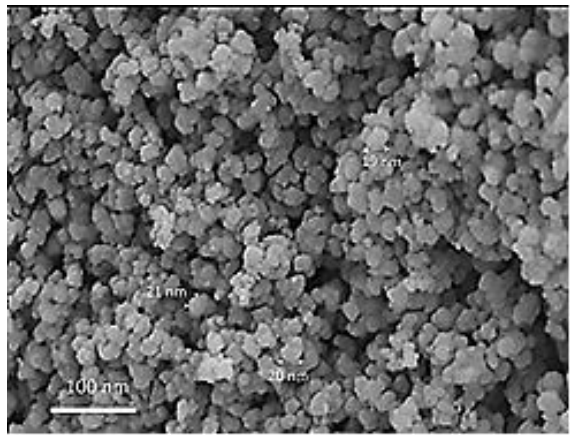

(a)

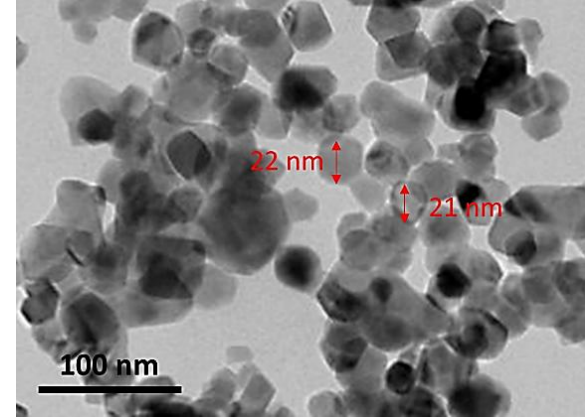

(b)

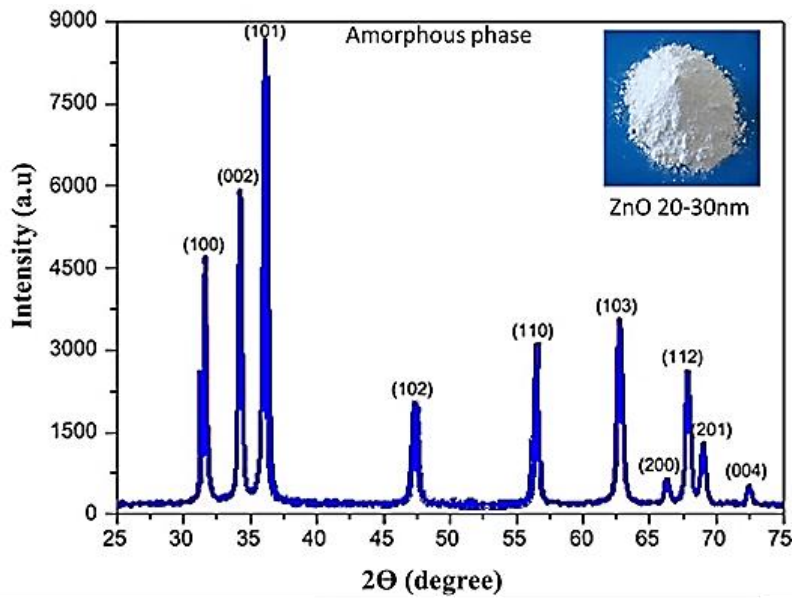

(c)

Fig. 2. a) Scanning Electron Microscopic image (SEM), b) Transmission Electron Microscopic image (TEM) of $\mathrm{ZnO} /$ water at wt. \% $=0.1$, and c) XRD pattern of $\mathrm{ZnO}$ nanoparticles 
Figs. 2a,b show the results of microscopic images taken from the nanoparticles before dispersion (SEM) and nanofluid samples (TEM). Fig. 2a presents the Scanning Electron Microscopic image (SEM) taken from the nanoparticles. As can be seen, particles are spherical with the same size of $20-30 \mathrm{~nm}$. No agglomeration is seen within the solid nanoparticles. Fig. 2b shows the Transmission Electron Microscopic image taken from the prepared sample at wt. \% $=0.1$. As can be seen, neither agglomeration nor clusters can be seen in the image. The estimated size in TEM image is in a good agreement with the size claimed by manufacturer and that of obtained from SEM image. All sizes were within the range of 20-30 nm.

Fig. $2 \mathrm{c}$ represents the XRD pattern of $\mathrm{ZnO}$ nanoparticles. As can be seen, the curve and also the characteristic peaks of the XRD pattern are broad because of the nano-size effect. Importantly, the peaks locations are in accordance with the reference pattern for $\mathrm{ZnO}$. Moreover, no other peaks are seen in the XRD pattern meaning that there is no impurity in the structure of nanoparticles. In addition, molecular structure (shape phase) of $\mathrm{ZnO}$ was found to be amorphous. This structure, due to its symmetric bonds, has higher thermal conductivity rather than other molecular structures, which is suitable for heat transfer applications.

\subsection{Thermo-physical properties of nanofluids}

Table 1 shows the experimentally measured thermo-physical properties of $\mathrm{ZnO}$ nanofluid at mass concentrations of $0.1-0.4$ at temperature $60^{\circ} \mathrm{C}$. As can be seen, thermal conductivity of the nanofluids increases, when concentration of nanoparticles inside the base fluid increases. For instance, at wt. \% $=0.1$, thermal conductivity of the nanofluid is 1.08 times higher than that of measured for the base fluid. This is mainly due to the internal thermal conductivity of $\mathrm{ZnO}$ nanoparticles inside the base fluid. Likewise, Brownian motion of particles is another reason for the enhancement of thermal conductivity. The Brownian motion of the particles not only creates micro-convection heat transfer within the base fluid, but also creates local agitation and turbulent spots in the bulk of base fluid. The former increases

Table 1.

Thermo-physical properties of $\mathrm{ZnO} /$ water nanofluids at $60^{\circ} \mathrm{C}$

\begin{tabular}{|l|c|c|c|c|}
\hline Physical propoerties $(m)$ & \multicolumn{4}{|c|}{ Enhancement ratio $\left(\frac{m_{n f}}{m_{b f}}\right)$} \\
\hline Mass concentration & wt.\%=0.1 & wt. \% $=0.2$ & wt. \% $=0.3$ & wt.\%=0.4 \\
\hline Thermal conductivity & 1.07 & 1.11 & 1.15 & 1.23 \\
\hline Density & 1.03 & 1.06 & 1.1 & 1.11 \\
\hline Viscosity & 1.04 & 1.07 & 1.11 & 1.14 \\
\hline Specific heat & 0.99 & 0.98 & 0.97 & 0.96 \\
\hline
\end{tabular}

Thermal conductivity, density, viscosity and specific heat of the base fluid are: $0.61 \mathrm{~W} / \mathrm{m}$. K, $0.998 \mathrm{~kg} / \mathrm{m}^{3}, 0.89 \mathrm{cP}, 4.187 \mathrm{~kJ} / \mathrm{kg} \mathrm{K}$, respectively. 
the energy transport inside the base fluid and enhances the thermal conductivity. The latter phenomenon results in the enhancement of convective heat transfer coefficient, as well. This is because particles can create a chain and cluster of conductive medium within the bulk of base fluid. In addition, according to the layer theory, a layer of liquid is formed around the particles and this layer has a thermal conductivity higher than the liquid and smaller than the solid. Thus, it can enhance the overall thermal conductivity, as well. The higher the concentration of nanoparticles, the higher the number of these layers, and as a result, higher thermal conductivity can be obtained. For density, due to the presence of the particles, relative mass of the nanofluid increases, which leads to the enhancement of density. As can be seen, with an increase in the mass concentration of nanoparticles, density increases.

Viscosity of the nanofluids is increased, when concentration of particles increases inside the bulk of the base fluid. For the specific heat, as the specific heat of $\mathrm{ZnO}$ particles is lower than that of water, therefore increasing the concentration of particles inside the base fluid decreases the specific heat of the nanofluids. Noticeably, the results were measured three times to ensure repeatability and productivity of the results. More importantly, properties were only measured at temperature $60^{\circ} \mathrm{C}$ and it was assumed that physical properties of the $\mathrm{ZnO}$ nanofluids remained steady at temperatures that ranged from $40-70^{\circ} \mathrm{C}$ and were equivalent to the measured values at $60^{\circ} \mathrm{C}$.

It is worth saying that the viscosity of nanofluids was measured using DVII + PRO digital viscometer (manufactured by Brookfield Co., Accuracy: $\pm 1.0 \%$ of reading/Repeatability: $\pm 0.2 \%$ ). Density was also measured using DMA 4500 ME (manufactured by Anton Paar Co., Accuracy: $\pm 1.0 \%$ of reading/Repeatability: $0.00001 \mathrm{~g} / \mathrm{cm}^{3}$ ). Thermal conductivity was also measured using DTC300 (manufactured by TA Instrument, Accuracy: $\pm 3 \%-8 \%$ depending on thermal resistance/Repeatability: \pm 1 to $\pm 2 \%$ depending on thermal resistance/Standard: ASTM E1530) and proved by Decagon KD2 pro. Specific heat was measured by DSC Mettler Toledo instrument (accuracy: $\pm 0.1 \%$ reading).

Likewise, variation of thermo-physical properties at temperature range of $25^{\circ} \mathrm{C}-80^{\circ} \mathrm{C}$ was found to be insignificant. Therefore, it is assumed that the experimental thermo-physical properties are constant during the experiments.

\section{Results and discussion}

Fig. 3 represents the dependence of the overall heat transfer coefficient on flow rate of nanofluid (Reynolds number) and on various mass concentrations of $\mathrm{ZnO}$ nanoparticles in water. As can be seen, with an increase in flow rate of nanofluid, not only average velocity and Reynolds number increases but also the overall heat transfer coefficient increases, too. For example, for wt. $\%=0.3$ at Reynolds number of 310 , the overall heat transfer coefficient is $380 \mathrm{~W} / \mathrm{m}^{2} \mathrm{~K}$, while at $\mathrm{Re}=600$, it is $700 \mathrm{~W} / \mathrm{m}^{2} \mathrm{~K}$. Interestingly, with an increase in mass concentration of nanofluid, 


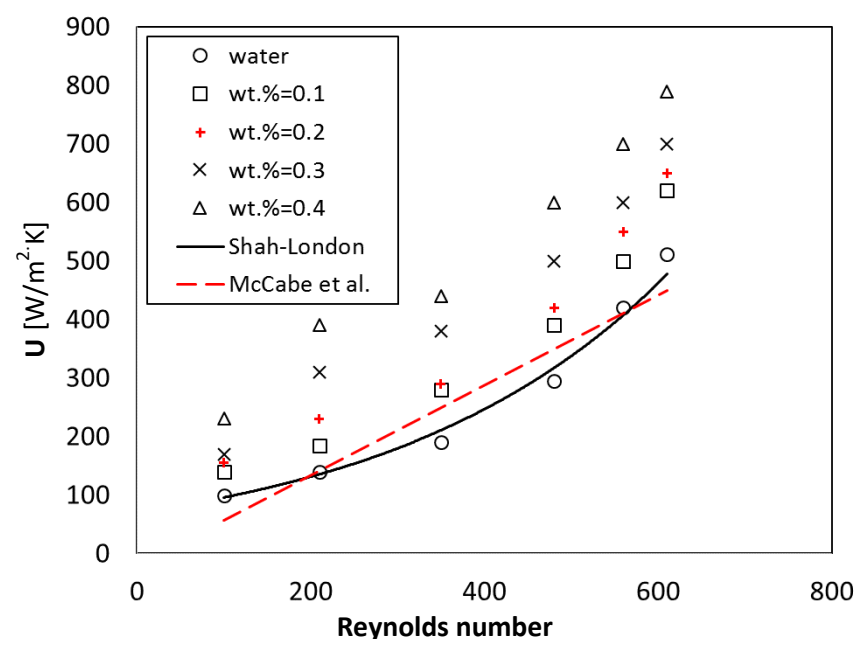

Fig. 3. Dependence of overall heat transfer coefficient on flow rate for different mass concentrations

the overall heat transfer coefficient increases up to wt. $\%=0.3$ and for mass concentrations $>0.3$, the heat transfer coefficient decreases. This phenomenon is largely due to the enhancement in viscosity of the nanofluid, instability due to the presence of high-concentration $\mathrm{ZnO}$ nanoparticles within the base fluid [27]. Likewise, in order to validate the results, the experimental data were compared to those of results obtained with well-known correlations such as London-Shah [29] and McCabe et al. [30], which both have been obtained for water. The absolute mean error (A.M.E) of the results for water was within the $6.1 \%$ and $11.8 \%$, respectively, obtained with the following equation:

$$
\text { A.M.E. }=\frac{1}{n} \sum_{1}^{n}\left|\frac{h_{\text {experimental }}-h_{\text {calculated }}}{h_{\text {experimental }}}\right| 100
$$

Fig. 4 shows the dependence of pressure drop on flow rate at different mass concentrations. As can be seen, for mass concentrations of $0.1 \%$ and $0.2 \%$, a penalty for pressure drop is registered. However, at higher concentrations such as $0.3 \%$ and $0.4 \%$, pressure drop is significantly larger than $0.1 \%$ and $0.2 \%$. This is associated with the enhancement in viscosity and presence of nanoparticles within the base fluid, which increases the friction factor as well [29].

Fig. 5 represents the dependence of friction factor on flow rate and for various mass concentrations of $\mathrm{ZnO}$ nanoparticles. As can be seen, with an increase in mass concentration of nanofluid, higher friction factor is seen. Noticeably, presence of nanoparticles and deposition on the internal walls can enhance the roughness and, as a result, an enhancement in friction factor parameter [30, 31]. Also, change in viscosity and density of the nanofluid can be another reason for the enhancement of friction factor. This is because a viscous and dense fluid can create higher 


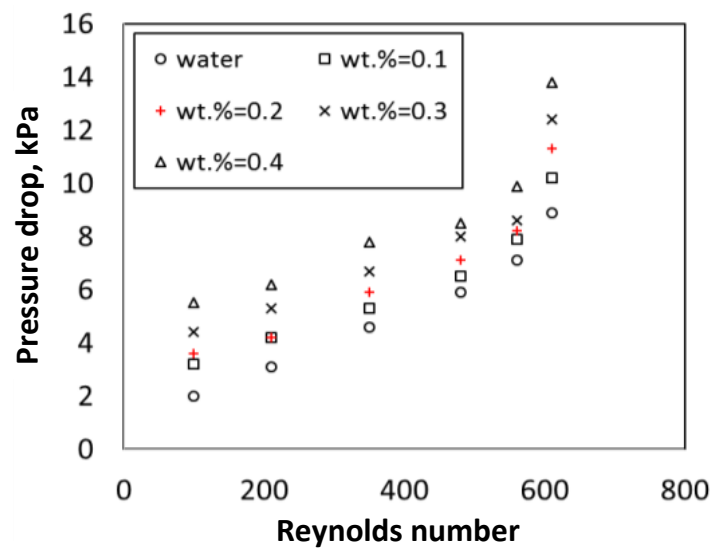

Fig. 4. Dependence of pressure drop on flow rate at different mass concentrations

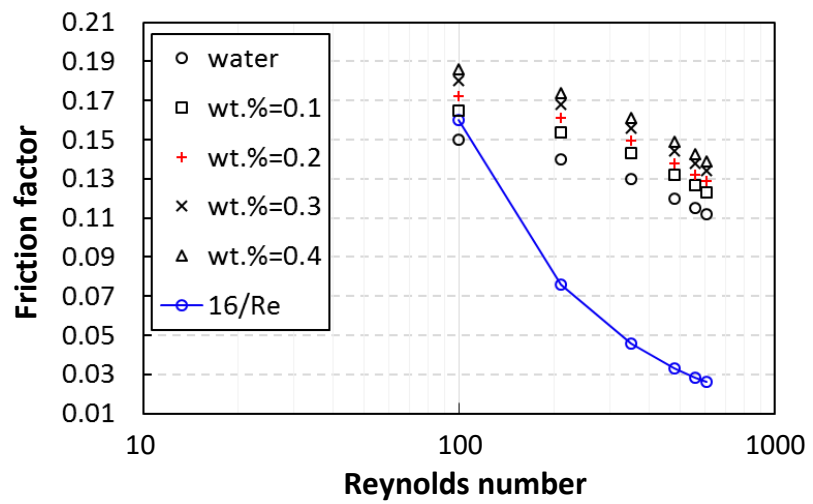

Fig. 5. Dependence of friction factor parameter on flow rate for different mass concentrations of $\mathrm{ZnO}$ nanoparticles

friction with the internal wall of the pipe. This phenomenon has previously been investigated in the literature $[32,33]$.

Fig. 6 represents the dependence of surface temperature of the heater on time for different nanofluids. As can be seen, surface temperature of the heater decreases when nanofluid is used instead of water. With an increase in mass concentration of nanofluid, the rate of reduction in temperature is increased. However, for wt. \% $=0.3$, due to the agglomeration of nanoparticles and due to the enhancement in pressure drop, temperature slightly increases.

A rough comparison between the results presented in Fig. 6 shows that the best cooling can be seen for wt. $\%=0.3$, and temperature of heater is $35 \%$ lower than in the case in which the heater is cooled down with water. For nanofluids at mass concentrations of $0.4,0.2$ and 0.1 , the temperature of heater is $32 \%, 30 \%$ and $27 \%$ lower than in the case in which the heater is cooled down with water. 


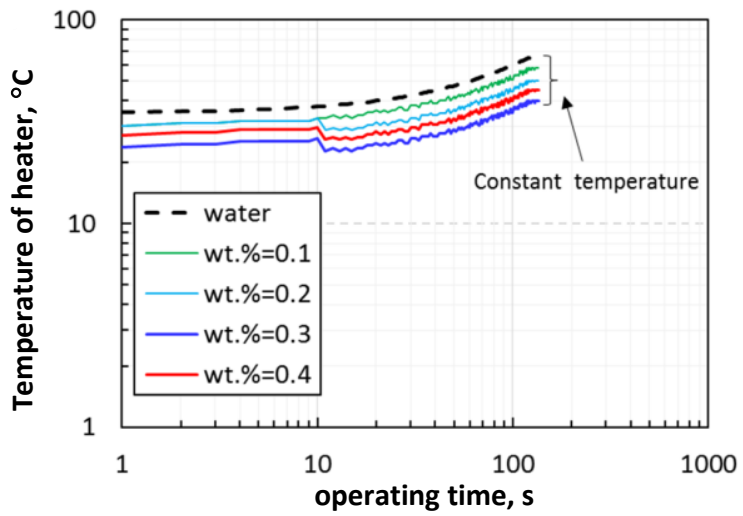

Fig. 6. Dependence of surface temperature of heater on operating time for different mass concentration of nanofluid

\section{Conclusion}

Experimental investigation on the cooling performance of a convective loop over a flat heater was performed and the following conclusions were made:

1. The presence of $\mathrm{ZnO}$ nanoparticles in the base fluid (here water) enhanced the heat transfer coefficient by $20.1 \%$. However, it was found that the there is an optimum for concentration, which is wt. $\%=0.3$ for our nanofluids. At higher concentrations, due to the enhancement in viscosity and pressure drop, a lower heat transfer coefficient was measured.

2. Nanoparticles intensified the pressure drop and it was demonstrated that, with an increase in mass concentration of nanoparticles, higher pressure drop was seen, which was mainly due to the enhancement of viscosity of nanofluid.

3. Nanoparticles enhanced the friction factor parameter due to the enhancement in wall roughness, density and viscosity of fluid. This is because the presence of nanoparticles increases the density and viscosity of base fluid, which causes more friction between fluid and internal wall of the pipe. In addition, deposition of nanoparticles increases the roughness of surface, which intensifies the friction factor parameter, as well.

Overall, $\mathrm{ZnO} /$ water is a promising coolant with high heat flux capability for micro-electronic cooling because there is a penalty for pressure drop, which should be considered. In addition, this penalty is a function of mass concentration of nanoparticles, which needs to be optimized depending on the application.

\section{Acknowledgements}

The authors of this work tend to appreciate Iran Nanotechnology Initiative Council for their financial supports. 
Manuscript received by Editorial Board, May 17, 2017;

final version, November 02, 2017.

\section{References}

[1] S.E. Ghasemi, A.A. Ranjbar, and M.J. Hosseini. Forced convective heat transfer of nanofluid as a coolant flowing through a heat sink: Experimental and numerical study. Journal of Molecular Liquids, 248:264-270, 2017. doi: 10.1016/j.molliq.2017.10.062.

[2] M.M. Sarafraz, A. Arya, F. Hormozi, and V. Nikkhah. On the convective thermal performance of a CPU cooler working with liquid gallium and $\mathrm{CuO}$ /water nanofluid: A comparative study. Applied Thermal Engineering, 112:1373-1381, 2017. doi: 10.1016/j.applthermaleng.2016.10.196.

[3] M. Nazari, M. Karami, and M. Ashouri. Comparing the thermal performance of water, ethylene glycol, alumina and CNT nanofluids in CPU cooling: Experimental study. Experimental Thermal and Fluid Science, 57:371-377, 2014. doi: 10.1016/j.expthermflusci.2014.06.003.

[4] S.E. Ghasemi, A.A. Ranjbar, and M.J. Hosseini. Experimental and numerical investigation of circular minichannel heat sinks with various hydraulic diameter for electronic cooling application. Microelectronics Reliability, 73:97-105, 2017. doi: 10.1016/j.microrel.2017.04.028.

[5] H.M. Hu, T.S. Ge, Y.J. Dai, and R.Z. Wang. Experimental study on water-cooled thermoelectric cooler for CPU under severe environment. International Journal of Refrigeration, 62:30-38, 2016. doi: 10.1016/j.jirefrig.2015.10.015.

[6] M. Rafati, A.A. Hamidi, and M.S. Niaser. Application of nanofluids in computer cooling systems (heat transfer performance of nanofluids). Applied Thermal Engineering, 45:9-14, 2012. doi: 10.1016/j.applthermaleng.2012.03.028.

[7] M.M. Sarafraz and S.M. Peyghambarzadeh. Nucleate pool boiling heat transfer to Al2O3water and $\mathrm{TiO} 2$-water nanofluids on horizontal smooth tubes with dissimilar homogeneous materials. Chemical and Biochemical Engineering Quarterly, 26(3):199-206, 2012. http://hrcak.srce.hr/87353.

[8] M.M. Sarafraz and F. Hormozi. Experimental study on the thermal performance and efficiency of a copper made thermosyphon heat pipe charged with alumina-glycol based nanofluids. Powder Technology, 266:378-387, 2014. doi: 10.1016/j.powtec.2014.06.053.

[9] M. Kamalgharibi, F. Hormozi, S.A.H. Zamzamian, and M.M. Sarafraz. Experimental studies on the stability of cuo nanoparticles dispersed in different base fluids: influence of stirring, sonication and surface active agents. Heat and Mass Transfer, 52(1):55-62, 2016.

[10] M.M. Sarafraz, F. Hormozi, and M. Kamalgharibi. Sedimentation and convective boiling heat transfer of CuO-water/ethylene glycol nanofluids. Heat and Mass Transfer, 50(9):1237-1249, 2014. doi: 10.1007/s00231-014-1336-y.

[11] M.M. Sarafraz and F. Hormozi. Comparatively experimental study on the boiling thermal performance of metal oxide and multi-walled carbon nanotube nanofluids. Powder Technology, 287:412-430, 2016. doi: 10.1016/j.powtec.2015.10.022.

[12] M.M. Sarafraz and F. Hormozi. Intensification of forced convection heat transfer using biological nanofluid in a double-pipe heat exchanger. Experimental Thermal and Fluid Science, 66:279-289, 2015. 10.1016/j.expthermflusci.2015.03.028.

[13] M.M. Sarafraz, F. Hormozi, and S.M. Peyghambarzadeh. Thermal performance and efficiency of a thermosyphon heat pipe working with a biologically ecofriendly nanofluid. International Communications in Heat and Mass Transfer, 57:297-303, 2014. doi: 10.1016/j.icheatmasstransfer.2014.08.020.

[14] M.M. Sarafraz, T. Kiani, and F. Hormozi. Critical heat flux and pool boiling heat transfer analysis of synthesized zirconia aqueous nano-fluids. International Communications in Heat and Mass Transfer, 70:75-83, 2016. doi: 10.1016/j.icheatmasstransfer.2015.12.008. 
[15] M.M. Sarafraz and F. Hormozi. Heat transfer, pressure drop and fouling studies of multi-walled carbon nanotube nano-fluids inside a plate heat exchanger. Experimental Thermal and Fluid Science, 72:1-11, 2016. doi: 10.1016/j.expthermflusci.2015.11.004.

[16] M.M. Sarafraz and F. Hormozi. Experimental investigation on the pool boiling heat transfer to aqueous multi-walled carbon nanotube nanofluids on the micro-finned surfaces. International Journal of Thermal Sciences, 100:255-266, 2016. doi: 10.1016/j.ijthermalsci.2015.10.006.

[17] M.M. Sarafraz, F. Hormozi, and S.M. Peyghambarzadeh. Pool boiling heat transfer to aqueous alumina nano-fluids on the plain and concentric circular micro-structured (CCM) surfaces. Experimental Thermal and Fluid Science, 72:125-139, 2016. doi: 10.1016/j.expthermflusci.2015.11.001.

[18] M.M. Sarafraz, F. Hormozi, and V. Nikkhah. Thermal performance of a counter-current double pipe heat exchanger working with $\mathrm{COOH}-\mathrm{CNT} /$ water nanofluids. Experimental Thermal and Fluid Science, 78:41-49, 2016. doi: 10.1016/j.expthermflusci.2016.05.014.

[19] M.M. Sarafraz, F. Hormozi, and S.M. Peyghambarzadeh. Role of nanofluid fouling on thermal performance of a thermosyphon: Are nanofluids reliable working fluid? Applied Thermal Engineering, 82:212-224, 2015. doi: 10.1016/j.applthermaleng.2015.02.070.

[20] S.M. Peyghambarzadeh, M.M. Sarafraz, N. Vaeli, E. Ameri, A. Vatani, and M. Jamialahmadi. Forced convective and subcooled flow boiling heat transfer to pure water and nheptane in an annular heat exchanger. Annals of Nuclear Energy, 53:401-410, 2013. doi: 10.1016/j.anucene.2012.07.037.

[21] M.M. Sarafraz, S.M. Peyghambarzadeh, and N. Vaeli. Subcooled flow boiling heat transfer of ethanol aqueous solutions in vertical annulus space. Chemical Industry and Chemical Engineering Quarterly, 18(2):315-327, 2012. doi: 10.2298/CICEQ111020008S.

[22] M.M. Sarafraz. Nucleate pool boiling of aqueous solution of citric acid on a smoothed horizontal cylinder. Heat and Mass Transfer, 48(4):611-619, 2012. doi: 10.1007/s00231-011-0910-9.

[23] M.M. Sarafraz, S.M. Peyghambarzadeh, and S.A. Alavifazel. Enhancement of nucleate pool boiling heat transfer to dilute binary mixtures using endothermic chemical reactions around the smoothed horizontal cylinder. Heat and Mass Transfer, 48(10):1755-1765, 2012. doi: 10.1007/s00231-012-1019-5.

[24] E. Salari, S.M. Peyghambarzadeh, M.M. Sarafraz, and F. Hormozi. Boiling thermal performance of tio2 aqueous nanofluids as a coolant on a disc copper block. Periodica Polytechnica. Chemical Engineering, 60(2):106-122, 2016.

[25] M.M. Sarafraz. Experimental investigation on pool boiling heat transfer to formic acid, propanol and 2-butanol pure liquids under the atmospheric pressure. Journal of Applied Fluid Mechanics, 6(1):73-79, 2013.

[26] M.M. Sarafraz and S.M. Peyghambarzadeh. Influence of thermodynamic models on the prediction of pool boiling heat transfer coefficient of dilute binary mixtures. International Communications in Heat and Mass Transfer, 39(8):1303-1310, 2012. doi: 10.1016/j.icheatmasstransfer.2012.06.020.

[27] M.H. Al-Rashed, G. Dzido, M. Korpyś, J. Smołka, and J. Wójcik. Investigation on the cpu nanofluid cooling. Microelectronics Reliability, 63:159-165, 2016. doi: 10.1016/j.microrel.2016.06.016.

[28] S.J. Kline and F.A. McClintock. Describing uncertainties in single-sample experiments. Mechanical Engineering, 75:3-8, 1953.

[29] R.K. Shah and A.L. London. Laminar Flow Forced Convection in Ducts: A Source Book for Compact Heat Exchanger Analytical Data. Academic Press, 2014.

[30] T.L. Bergman and F.P. Incropera. Fundamentals of Heat and Mass Transfer. John Wiley \& Sons, 2011. 
[31] W. Duangthongsuk and S. Wongwises. Heat transfer enhancement and pressure drop characteristics of $\mathrm{TiO}_{2}$-water nanofluid in a double-tube counter flow heat exchanger. International Journal of Heat and Mass Transfer, 52(7):2059-2067, 2009. doi: 10.1016/j.ijheatmasstransfer.2008.10.023.

[32] R.S. Vajjha, D.K. Das, and D.P. Kulkarni. Development of new correlations for convective heat transfer and friction factor in turbulent regime for nanofluids. International Journal of Heat and Mass Transfer, 53(21):4607-4618, 2010. doi: 10.1016/j.ijheatmasstransfer.2010.06.032.

[33] M. Chandrasekar, S. Suresh, and A.C. Bose. Experimental studies on heat transfer and friction factor characteristics of $\mathrm{Al}_{2} \mathrm{O}_{3}$ /water nanofluid in a circular pipe under laminar flow with wire coil inserts. Experimental Thermal and Fluid Science, 34(2):122-130, 2010. doi: 10.1016/j.expthermflusci.2009.10.001. 